\title{
Prevention of injuries to children and young people: the way ahead for the UK
}

\author{
Elizabeth Towner, Heather Ward
}

Injury in children and young people is not inevitable. Accidents and the injuries that result from them, are not chance events. Patterns of injury can be identified that reflect a person's age, the environment in which children and young people live, and the activities in which they are engaged. Greater understanding of the causes of injury can help us in the development of effective preventive strategies. Opportunities to prevent injuries occur through a range of educational, environmental, and legislative approaches. We need to fully mobilise these opportunities to save lives and improve the health of children and young people in the UK.

When one considers the worldwide public health importance of injuries to this age group, it is surprising that only a small number of potential interventions have been rigorously evaluated. Moreover, of those with proven efficacy, many prevention measures have been poorly implemented. But there are a number of interventions that we know to be effective and others that have the potential to be effective. In this chapter, we attempt to distill the essence of injury prevention by first providing an overview of the broad approaches. We then discuss the specific interventions and methods that have been shown to be effective. The broader context of policies and cultures that affect injury are then set out. Finally, we pull together the strands to consider what is still required for more effective preventive action in the UK.

\section{Approaches to injury prevention}

The problems of injuries to children and young people stem from their complexity and wide ranging nature. Typical examples include an 18 month old child reaching up in a kitchen and pulling down a mug of scalding tea, an 8 year old falling from a climbing frame in a playground and fracturing her leg, or a 12 year old pedestrian knocked down by a car and receiving multiple injuries. These different types of injury occur in different environments and each has a range of possible counter measures. The multifaceted nature of the factors that contribute to injury: characteristics of the child or young person, parent, and family; the environment; social deprivation and exposure to risk - all need to be kept in mind when considering possible preventive strategies.
Generally, there are three broad approaches to prevention: education, environmental modification, and legislation and its enforcement, although in practice there can be much overlap between these.

\section{EDUCATION}

Traditionally education in this field has been seen in an excessively narrow way. Critics of its effectiveness have chosen to focus on changing individual decision making by children and parents, such as campaigns to increase bicycle helmet use and road safety education programmes. But, education also encompasses the education of professionals and policy makers and can include lobbying and advocacy. It also shapes the culture by developing the beliefs and attitudes of the general public, that create the imperatives for governments to act. ${ }^{1}$

ENVIRONMENTAL MODIFICATION

Environmental modification or engineering involves the design of products or of the built environment to reduce the potential for injury. Large scale measures adopted in urban traffic safety schemes can include measures to redistribute traffic and reduce its speed, and safety improvements in individual roads can be implemented. On a smaller scale, physical barriers, such as window bars, can prevent children from falling. Bicycle helmets and protective equipment, such as mouth guards for rugby players, can reduce the consequences of head or facial injuries.

LEGISLATION

Legislation or regulation can be used to reinforce safety practices. At one end of the spectrum these approaches include a single action that offers passive protection to vulnerable recipients. Examples include the control of nightwear flammability and design changes to banisters. Avery and Jackson ${ }^{2}$ provide a useful summary of children's products covered by regulations or standards in the UK. At the other end of the spectrum, legislative approaches can require repetitive action-for example, the use of car seat belts or bicycle helmets. Intermediate between the two are child resistant containers to prevent poisoning and fencing of domestic swimming pools, each of which offer a degree of passive protection when used correctly. 
What interventions and methods have been shown to be effective?

In 1986 a World Health Organisation (WHO) report highlighted the fact that, despite the worldwide importance of unintentional injuries, there was a lack of studies that evaluated the effectiveness of preventive measures. ${ }^{3}$ In the decade since the WHO review there has been considerable growth, both in primary studies and in systematic reviews of effectiveness. ${ }^{4-11}$ This section draws on these reviews of the evidence and summarises what has been found to work in the road, home, leisure, and work environments, and in broader community based interventions.

\section{ROAD ENVIRONMENT}

In the UK, as in most higher income countries, injuries in the road environment are the leading cause of injury and death in children and young people. Here we examine interventions to prevent pedestrian, cyclist and motor cyclist, and car occupant injuries.

\section{Pedestrian injuries}

Accidents involving injury to child pedestrians on urban roads are more widely scattered spatially than those involving adults and occur more frequently on the residential roads near to where the children live. Because the accidents are more scattered, they are less susceptible to road engineering modifications suitable for high risk sites. This has led to the development of an area-wide approach. This uses traffic management and traffic calming techniques to encourage drivers to use other roads to achieve a safer distribution, and to manage the speed of traffic, so that it circulates more safely, especially on residential roads where there are children. ${ }^{12}$ The Department of the Environment, Transport and the Regions is currently funding a "Safer City Project" in Gloucester, where a strategic and interdisciplinary approach to road safety is being implemented with the aim of reducing the number of casualties in the city by $30 \%$. The approach encompasses changes to the road environment, road safety education, and enforcement.

Vehicles can be designed to reduce the consequences of pedestrian injuries and examples include reducing bumper height, ${ }^{13}$ and the banning of "bull bars" on cars. There is a strong link between vehicle speed and the severity of injury sustained by pedestrians after a collision. ${ }^{14}$ The introduction of $20 \mathrm{mph}$ speed limit zones in the UK resulted in local reductions of $70 \%$ in child pedestrian and $48 \%$ in child cyclist accidents. ${ }^{15}$ Road safety education campaigns have often been targeted at children and their parents rather than at car drivers. A programme in Canada targeted both drivers and pedestrians and used a combination of education, engineering, and enforcement measures to increase the safety of pedestrians at crossings. This programme produced an increase in motorists yielding the right of way to pedestrians. ${ }^{16}$

One of the problems of road safety education programmes aimed at children and their carers is the complexity of the pedestrian task; Rivara et al estimated that road crossing can involve up to 26 different tasks to negotiate traffic successfully. ${ }^{17} \mathrm{~A}$ recent examination by developmental psychologists of road safety education programmes has concluded that most do not take into account how children learn and that training in crossing skills in the real road environment is essential. ${ }^{18}$

Traffic clubs have been organised in a number of countries, but have only achieved mixed results. In the UK, the "Tufty Club" has been popular among schools and parents of preschool children. Knowledge gains were reported in one study, ${ }^{19}$ but not in another. ${ }^{20}$ The Eastern Region traffic club in England showed an effect on children's behaviour; running ahead of parents when out walking was reduced and there was some effect on casualty reduction (children emerging from behind parked vehicles). ${ }^{21}$ Norway's traffic club has employed practical instruction and training by parents. ${ }^{22}$ The lower casualty rates for members could probably be explained, however, by selective club membership. Similar traffic clubs have been introduced by other European countries.

When both parents and children have been given pedestrian skills training, programmes in the USA and the Netherlands have demonstrated some improvements. ${ }^{17}{ }^{23}$ In particular, parents set better examples and gave more verbal instructions. Other small scale experimental studies have concentrated on specific pedestrian tasks, for example timing skills to improve efficiency in making use of gaps in traffic $^{24}$ and in finding safe places to cross. ${ }^{25-27}$ These studies have found that training young children can lead to reported change in behaviour.

Based on methods used in experimental studies, the UK "Let's decide walkwise" pedestrian training programme for 5-8 year olds has been developed for schools. It has a curriculum component, complemented by practical roadside training. Children in participating schools showed improvement in crossing behaviour compared with control schools. ${ }^{28}$ Similar results were found in an Australian programme that also used practical roadside training. ${ }^{29}$ But practical training is time consuming and labour intensive and one way around this has been to adopt an approach using community volunteers. Local volunteers were recruited to carry out roadside training of children, working in cooperation with schools and project staff in Drumchapel, Glasgow. The judgments and behaviour of trained children improved substantially after training. Training local people in road safety also has the benefit of the local community suggesting their own solutions to local problems rather than relying on external expertise. ${ }^{30}$

\section{Cyclist and motorcyclist injuries}

Within the field of cycle safety, the greatest number of studies relate to the wearing of cycle helmets. There is good evidence that cycle helmets offer protection from head injury. A population based case-control study found that the use of helmets decreased the risk of head 
injuries by $85 \%$ and reduced the risk of brain injuries by $88 \% .^{31}$ In high velocity impacts, helmets are less effective. ${ }^{32}$

It has been argued, however, that concentration on promoting helmets diverts attention from improving the environment for cyclists, such as greater use of cycleways, or other means to better separate cyclists from other road vehicles. ${ }^{33}$ The effectiveness of separate lanes for bicycles has not been evaluated. ${ }^{10}$

An early campaign to increase cycle helmet use in Seattle included a range of educational methods and agencies and resulted in sharp increases in observed helmet wearing. It was highly focused in terms of age group and message and also addressed the barrier of cost. ${ }^{34}$ In the United States, a comparison was made of education alone, and education combined with legislation in different states, and the latter was found to be far more effective..$^{35}$ Victoria, in Australia, after a decade of educational campaigns, introduced the first legislation requiring cyclists to wear helmets. ${ }^{36}$ Considerable reductions in head injuries and deaths have been observed, most of which can be attributed to the legislation, but some may also be attributed to a reduction in cycling. ${ }^{37}$

Legislation on motorcycle helmet use has similarly resulted in a reduction in motorcycle fatalities. ${ }^{11}$ In the United States repeal of motorcycle helmet use has been followed by an increase in fatalities of 25-40\%. ${ }^{11} 3839$

There have been few studies that have evaluated the effects of cycle training. In Canada, a brief skills training programme aimed at primary schoolchildren was not effective in improving safe cycling behaviour, knowledge, or attitudes. ${ }^{40}$ In the Netherlands, comparisons of practical and theoretical training of young cyclists has shown little effect on safe behaviour at traffic intersections. ${ }^{41}$ Munro et al found little evidence that training reduced motorcycle injury rates. ${ }^{11}$ One study did find an effect in reducing risk but the size of the effect diminished after two years. ${ }^{1142}$ There is some evidence that trained riders make greater use of protective clothing. ${ }^{43}$

Car occupant injuries

Safety within cars involves a number of design changes to protect passengers from contact with hard objects or surfaces in the interior of the vehicle. ${ }^{9}$ These include energy absorbing steering columns, increased padding on interior contact points, and enhanced side impact protection. $^{10}$

Other measures concerned with safety within cars relate to seat belts and child safety restraints. Both have been studied thoroughly and there is now considerable evidence that these are highly effective in reducing injury and death. The problem is for them to be used more widely and properly. In the UK, legislation for mandatory front seat belt wearing in cars was introduced in 1983. Lowne et al found a marked reduction in injuries to 11-14 year old children travelling in the front seat. ${ }^{44}$ In 1989, legislation was introduced into Britain, making it compulsory for a child under 14 to be restrained in the rear of the car, providing a restraint was available. In 1992, observed seat belt use for child rear occupants declined with age, so that $88 \%$ of children under the age of 1 were being restrained, compared with $60 \%$ in the $10-13$ age group. ${ }^{45}$

\section{HOME ENVIRONMENT}

Although the roads are the leading cause of injury deaths in childhood (about one child per day), the home remains the setting for a significant number of deaths and large numbers of non-fatal injuries. Preschool children are particularly vulnerable in the home environment, not just because homes are inherently unsafe, but because this is where these children spend most of their time. The domestic environment presents a greater problem than the road environment because it is less amenable to the types of regulatory approach than are available in the road environment. Local councils have a statutory responsibility to implement road safety, but for safety promotion within the home, there is no statutory requirement and staff dedicated to home safety issues vary.

The range of potential hazards in the home is vast and exposure to these varies as a child develops. Injury types include house fires, other burns and scalds, falls, poisonings, drownings, choking and suffocation, and entrapments and lacerations from glass and other sharp objects. Sinnott points out that children make use of their homes, "in ways that seem to them to be reasonable, but have not apparently been foreseen by the designer". ${ }^{46}$ These uses include children who, "crawl about the floor, climb onto the window ledge, squeeze through stair balustrades, slide down the stair hand-rail, swing on the gate, run from room to room, and ride bikes inside as well as out". ${ }^{46}$

In this section we look in more detail at specific interventions aimed at reducing three important types of home injury: house fires, falls, and scalds. Fires are the leading cause of death in childhood home injuries and rank second after pedestrian injuries as the cause of unintentional injury deaths in children under 15 years in the UK. There is a steep social gradient for childhood deaths from house fires, with children in social group $\mathrm{V}$ being nine times as likely to die in a house fire than those from social group I. ${ }^{47}$ Fall injuries result in relatively few deaths in childhood, but are the major cause of hospital admissions and accident and emergency attendance. ${ }^{48}$ Scald injuries represent a small proportion of injuries, but they are among the most distressing and painful injuries a child can receive and may result in long term disfigurement and disability. ${ }^{49}$

\section{House fires}

Very young children are particularly vulnerable in house fires because they depend on adults for assistance with escape. When a house fire occurs, one of the most important risk factors for death is the absence of a smoke alarm. ${ }^{50}$ Smoke alarms are a reliable, inexpensive means of providing an early warning. ${ }^{51} \mathrm{~A}$ number of studies aimed at increasing smoke alarm use have been evaluated. ${ }^{52-54} \mathrm{~A}$ recent, 
highly effective programme was a targeted intervention in a high risk city centre area of Oklahoma City in the United States that involved a smoke alarm "give away" programme. An $80 \%$ reduction in the incidence of injuries from residential fires was recorded in the target area. ${ }^{55}$ The widespread use of such an environmental modification can also be achieved through legislation: a comparison of smoke detector legislation in two states in the United States showed a reduction in fatal fires when smoke alarms were required by law in all homes. ${ }^{56}$ Another study showed that education could also increase smoke alarm use: in this case paediatricians' endorsement of the alarms during "well child" clinics resulted in a significant increase in installation. ${ }^{57}$ But this was a predominantly middle class sample, and targeted intervention in more deprived communities (such as that in Oklahoma City) could potentially provide greater health gains. Attention needs to be paid, not just to increasing the ownership of smoke alarms, but also to their correct installation, positioning, and continued maintenance. Data from fire brigades in the UK show that in over half the cases where a smoke alarm did not operate in a house fire, the battery had been removed. ${ }^{58} 59$

Smoke alarms provide an early warning of a house fire, but other solutions include tackling the cause of the fires and reducing the amount of toxic smoke. Smokers' materials, such as matches, lighters, and cigarettes are a frequent cause of fires in the home: an estimated $35 \%$ of deaths and $20 \%$ of non-fatal injuries are caused by these materials. ${ }^{58}$ Children living in the homes of smokers are more at risk from house fires and reducing smoking would have this added public health benefit. Cigarette lighters and matches pose a special risk to children. In the United States, Canada, and Australia there are requirements that all lighters are child resistant, but there are no similar requirements at present in the European Union. ${ }^{60}$ Research is currently under way in the UK on the feasibility of producing child resistant match boxes. ${ }^{61}$ Reductions in the amount of toxic smoke produced in a fire have been achieved through a ban on the most hazardous grades of foam in furniture ${ }^{60}$ Deaths have fallen from 51 per 1000 fires in 1988 to 34 in 1991, stabilising at 40 subsequently. ${ }^{62}$

Falls

The circumstances in which falls occur relate to the child's developmental stage and their exposure to particular environments. ${ }^{63}$ Safety gates are often used to prevent falls on stairs. Although their use has been associated with lower risk ${ }^{64}$ no specific study has evaluated their value in the home. ${ }^{65}$ There is evidence that babywalkers are also associated with severe fall injuries, in particular with head injuries. ${ }^{66}$ Consequently there is growing pressure in the United States and Australia to ban babywalkers. Falls from greater heights, for example from windows and balconies, result in more serious injury and death. Building design changes can reduce these injuries. ${ }^{6768} \mathrm{~A}$ campaign, evaluated in New York, that pro- vided free window guards to families living in apartments and was reinforced by mass media campaigns, home inspections, and local regulations for landlords showed a 50\% decrease in falls occurring and a $35 \%$ decrease in mortality ${ }^{69}$

Scalds

Scalds caused by tap water, bathing, and by hot beverages have different profiles that require different preventive strategies. ${ }^{70}$ Lowering the temperature of tap water has been achieved through legislative approaches and broadly based educational campaigns and have reduced the number of child casualties. ${ }^{71}$ Scald injuries to young children reaching up and pulling kettle flexes would be reduced by the greater use of coiled or short kettle flexes, but no evaluated study has been reported. ${ }^{7}$ Scalds from cups and mugs pose a difficult problem. In Australia, there have been attempts to develop a spill resistant mug $^{72}$ but widespread use of such mugs may not be acceptable. Mass media campaigns aimed at burns prevention have resulted in some gains in knowledge, but have not been found to reduce injury. ${ }^{73}$ Moller suggests that a behavioural solution is the only possible one for preventing beverage scalds and needs to be targeted at the parents of children aged 6 to 36 months. ${ }^{70}$

These three examples of injuries that cause severe, frequent, or particularly distressing injuries in the home serve to illustrate the wide range of circumstances of injuries and the numerous preventive strategies that arise from these. There are many more examples: poisonings, where child resistant packaging of medicinal and non-medicinal agents has been shown to be effective; lacerations from glass which have been prevented through the use of safety glass, required under Building Regulations in new housing in the $\mathrm{UK}^{60}$; and drownings in the bath where adult supervision has met with some success. ${ }^{74}$

\section{General approaches}

Some campaigns have attempted to target a wide range of home injuries. One such campaign in a deprived community in Newcastle supplemented a mass media campaign (the television "Play it Safe" campaign) with individual health visitor home visits. Sixty per cent of the intervention group (who had received a home visit) made some physical change to their homes, compared with $9 \%$ of a control group who had only been encouraged to watch the television series. ${ }^{75}$ The severely disadvantaged families in Newcastle responded positively because the advice offered was small in amount, specific, and concrete.

In other studies of home hazards, the results have been less conclusive. ${ }^{76-78} \mathrm{~A}$ home visitation programme from the United States had a broader emphasis, attempting to also tackle problems associated with social deprivation. This targeted poor, unmarried teenagers during their pregnancy and first two years of their infants' lives. In addition to home hazards and safety practices, issues such as child abuse and neglect, mothers' warmth, and control of their 
children, were studied. The mothers who had received home visiting support had fewer hazards in their homes, but there was no effect on how they stored poisonous substances or on whether they used child safety restraints in their cars. ${ }^{79}$

Roberts et al analysed a number of home visiting programmes for their effect on injury and child abuse outcomes. Although they found few that had been rigorously evaluated, they concluded that the results were sufficiently encouraging to call for further evaluation of the effects of social support on the prevention of childhood injury. ${ }^{80}$

LEISURE ENVIRONMENT

Large numbers of children and young people are injured every year in informal leisure activities and actively participating in sports. Sports related injuries are an important cause of hospital admissions in the UK, particularly for school aged children, and they make a considerable contribution to impairment and disability ${ }^{81}$ But the leisure environment has been largely ignored as a setting for prevention programmes. Although the outdoor leisure environment forms part of the "public domain" where regulation and enforcement are more feasible than within the home, this setting suffers from the fact that no one agency has the remit to prevent injury.

All forms of sport and recreation present some injury risk to children and young people. There is a balance to be achieved between the promotion of sports and recreational activities which encourage both physical and social development, and reducing the risk of injury (particularly the most serious injuries) through the use of safety equipment, appropriate supervision, and training.

\section{Playground injuries}

The safety of children in public playgrounds is a complex interaction of a number of factors: the type, height, and maintenance of the equipment, the type and maintenance of the surface, the number of children playing and the type of play, the quality of supervision, and weather conditions. ${ }^{82}$ There is no direct experimental evidence that restricting the height of equipment or resurfacing playgrounds with rubber or bark reduce injury in children. But there is a growing body of indirect, epidemiological evidence that suggests that equipment heights below 1.5 metres and impact absorbing surfaces are associated with less frequent and less severe injury. ${ }^{83} 84$

\section{Sports injuries}

There is a need for more investigation into the value of protective devices in sporting activities. Helmets are of known value for horse riders $^{85}$ and a study of mouthguards in rugby players showed that they were associated with reduced dental injuries. ${ }^{86}$ Evidence from Australia of a high incidence and severity of eye injuries in racket sports (especially squash and badminton) has led to the development of more effective and acceptable eye protection. ${ }^{87}$ Rule changes in some sports, such as American football and ice hockey, have been effective in reducing certain types of injuries. ${ }^{11}$ An educational programme for recreational runners which included warm-up and cool-down exercises, had no effect on injury rates but had some influence on knowledge and attitudes. ${ }^{11} 88$ But a programme of warm-up exercises, protective equipment, and rehabilitation directed at elite soccer players in Sweden reduced injuries by $75 \%$ when supervised by medical personnel, and by $50 \%$ when supervised by coaches. ${ }^{89}$

\section{Drownings}

Although not a signficant problem in the UK, barriers for domestic ponds and swimming pools have been shown to reduce injury deaths and injury risk, particularly in those under 5, in Australia and the United States. ${ }^{90-95}$ Pool barrier legislation has been estimated to reduce domestic pool deaths by half. ${ }^{95}$ Adult supervision is clearly important in the prevention of drownings among young children, but drowning in rivers, canals, lakes, and the sea is predominantly a problem of older boys who play unsupervised. ${ }^{96}$ Teaching children to swim may offer some protection..$^{97}$ The provision of guards on beaches and popular swimming areas are associated with a reduction in drowning deaths. ${ }^{909899}$

WORK ENVIRONMENT

Injury among children and young people in the work environment has received little attention in the literature. ${ }^{100101} \mathrm{~A}$ British study conducted in 1991, estimated that $40 \%$ of the population under 16 years was working, and over a third of these had had an accident at work in the past year. ${ }^{102}$ Agricultural injuries are a signficant component of injuries in the work envionrment for both children and adults. ${ }^{103}{ }^{104}$ Cameron et al have analysed fatal farm accidents to children in Britain over a four year period and found that tractor related injuries were the most serious farm related injuries. ${ }^{103}$

Tractor related deaths in children have declined since safety regulations on design have been introduced. Munro et al only report one example of an intervention specifically targeted at young people at work. ${ }^{11}$ This was an educational campaign conducted by Corcoran in the United States, but a full evaluation of the study was not carried out. ${ }^{105}$

\section{COMMUNITY BASED APPROACHES}

Community based approaches offer ways in which a broad range of interventions can be introduced that may complement and reinforce each other in particular geographical areas. They also represent a shift from a focus on individual responsibility to a social responsibility. ${ }^{99}$

Falköping in Sweden was one of the earliest communities to develop a broad based approach to injury prevention and has served as a model for initiatives in many parts of the world. ${ }^{106}$ The Safe Community network fosters this approach. ${ }^{107}$ Successful elements in the community based approach are good local 
data, interagency collaboration, an action committee to lead the programme, and time to develop local networks and a range of local programmes. Good local data on injury are needed to stimulate local interest, target specific interventions, and to evaluate the effect. The synergistic effect of educational, environmental, and legislative approaches can be achieved when a variety of agencies work together in a coordinated manner.

In Falköping there was a strong emphasis on the education of policy makers and health professionals using training sessions. Greater public awareness was achieved through harnessing the power of the local media. ${ }^{106}$ An American programme in a poor African-American inner city community also achieved some success the recruitment of community volunteers to coordinate and involve their neighbours in home hazard reduction. ${ }^{108}$ "Cascade" training methods were used to train the trainers. Another American programme, targeted at a disadvantaged community, included the renovation of playgrounds, the involvement of children in safer or supervised activities, the provision of injury and violence prevention education, and the provision of safety equipment. ${ }^{109}$ The community based approach allows the combination of such different types of intervention.

The community based studies harnessed the efforts of a range of agencies at a local level. For example, the Harlem Safe Kids-Healthy Neighborhoods programme recruited 26 organisations in its endeavours. ${ }^{109} \mathrm{~A}$ range of programmes is important in the community based approach. The Shire of Bulla programme in Australia developed 113 strategy activities over its first three years. ${ }^{110}$ To successfully work with a range of agencies in a variety of local programmes a long term time commitment is required. The Harstad programme in Norway continued for a period of 7-9 years, which allowed networks and a range of local programmes to develop. ${ }^{11-113}$

The community based programmes that have been evaluated have usually only included one intervention and one control community. The Statewide Child Injury Prevention Program (SCIPP) in Massachusetts is a notable exception, with nine intervention and nine control communities. Its intervention, however, only took place over a 22 month periodfar shorter than in many of the other studies reported. ${ }^{114}$ Lessons from a range of community based studies suggest that we need to combine robust evaluation methods using a range of different intervention and control communities, with well designed interventions. Community strategies lay the foundation for interventions, but require access to knowledge about effective strategies, if they are to produce reductions in injury. Their ultimate effectiveness, however, has not been conclusively demonstrated.

\section{The wider context}

Childhood injury patterns and the specific preventive interventions that have been proved to work, do not exist in a social, cultural, or politi- cal vacuum. Transport, land use, housing, social, and fiscal policies all affect injury. Cultural factors affect the way in which people behave and respond to the environment in which they live and to the acceptance of legislation or regulation. Underpinning these issues are the value we place on children and young people and on individual and social rights versus responsibilities. We look here in more detail at the effects of land use and transport policies and the impact of deprivation.

Land use and transport policies have a significant influence on where children live, where they go to school, how they use the road environment for play and for moving from place to place. National and local policies have an impact on the speed, location, volume, and composition of traffic which, in turn, affects the number and severity of pedestrian, cyclist, and car occupant casualties. There is a strong link between vehicle speed and the severity of injury sustained by pedestrians. ${ }^{14}$ Closing of streets, redirecting traffic, and bypassing residential neighbourhoods reduces pedestrian exposure to traffic.

Increased traffic volume can also influence how people use the road environment as pedestrians. Hillman et al believe that parental fears about increased traffic has limited children's independent mobility, both in terms of walking and as users of public transport, and has increased the amount of time parents transport children in cars. ${ }^{15}$ The composition of traffic is also significant. Gilbert and McCarthy found in an analysis of cyclist deaths in London, that heavy goods vehicles were much more frequently involved than expected, both in relation to the proportions of traffic in London or compared with national data on vehicles. ${ }^{116}$ Policies affecting the private/public mix of traffic can affect injury rates: when subsidies were removed from public transport in London, traffic levels increased, leading to increased road casualties. ${ }^{117}$ Hillman et al argue that 'children's issues in transport planning have been marginalised by policies accommodating the growth in the demand for motor transport". ${ }^{115}$

In the UK, greater weight has increasingly been given to the needs of pedestrian and cyclists. This can be seen in the development of a cycling strategy, ${ }^{118}$ and a walking strategy and new targets for injury reduction are soon to be published by the Department of Transport.

Policies that concern other land uses, such as the location of shopping centres or health centres, ${ }^{119}$ can also generate traffic that, in turn, influence injury rates. Policies that relate to schools have particular relevance to children's travel patterns. In the 1970s in England an increase in school size was accompanied by increased school journey time and Preston observed a corresponding increase in child casualties on these journeys. ${ }^{120}$ Increased parental choice for school allocation has the potential to increase the catchment area of schools with children travelling longer distrances to more popular schools. Local transport policies could take into account 
school catchment areas and children's school journeys.

Different housing types and their urban location (for example city centre or suburban) have different child road casualty rates. Postwar housing estates in the UK have lower injury rates than streets of Victorian terraced houses with few or no gardens, few garages, and much on-street parking. ${ }^{121}$ Council housing policies determine whether families with children are housed in high rise flats and whether gardens or play areas are available. These policies also effect the quality and location of temporary accommodation for homeless families.

The internal design of the home is also important, particularly in relation to injuries sustained by preschool children. The number of stairs, the way in which windows open, and how balconies are designed are all important examples. Child safety can also be enhanced by features such as low level hand rails on stairs. Homes are often designed with the needs of adults rather than children in mind. ${ }^{60} \mathrm{~A}$ will is required by architects and builders to include such measures, or pressure must be brought to bear on them to do so.

Perhaps the most important aspect of the wider context relating to injury is that of deprivation. The standard of living and its distribution have a powerful impact on people's health. ${ }^{122}$ There is clear evidence in the UK that childhood injuries are strongly linked to deprivation $^{123}$ and that socioeconomic mortality differentials for children are increasing. ${ }^{124}$ In the UK over the last 20 years the gap between the richest and poorest has increased greatly and the resulting inequality has affected some age groups more than others. The reasons for increasing inequalities are complex but include higher unemployment, the polarisation between two earner and no-earner couples, rising self employment, and a greater emphasis on indirect taxes rather than direct taxes (the latter have a greater effect on less affluent individuals). ${ }^{125}$ Children as a group are particularly vulnerable to these changes: in $1992 / 93,33 \%$ of children lived in poverty (defined as below $50 \%$ of average income after housing costs). This contrasts markedly with a figure of $10 \%$ of children in $1979 .{ }^{126}$

Poverty is particularly marked in the children of single parents. An estimated $47 \%$ of single parents live in poverty, compared with $20 \%$ of two parent families. ${ }^{126}$ Poverty, combined with poor housing conditions and social isolation, helps to explain some of the increased injury rates for the children of lone mothers. Roberts and Pless advocate an antipoverty strategy through the greater provision of day care facilities. This could have an important effect on the health and welfare of single mothers and their children by transforming their social position, while at the same time providing a safer environment for their children. ${ }^{127}$

\section{Conclusions and recommendations}

This section has attempted to describe the current state of knowledge on the prevention of unintentional injury in children and young people, and place it in the context of wider cultures and policies that affect these age groups. Injuries are not inevitable: they can be prevented. But their causes are complex and multifaceted and a wide range of countermeasures are required.

The way ahead for the UK is to generate more activity in injury prevention programmes through the wider implementation of evidence based approaches, and to stimulate better quality research in the field.

IMPLEMENTING EVIDENCE BASED INTERVENTIONS AND APPROACHES

Effective interventions and approaches need to be implemented in a far more widespread manner (implementation of injury prevention is explored in more detail in section 4). These interventions are summarised below.

Interventions that have been demonstrated to reduce injury mortality or morbidity include:

- Area wide urban safety measures to reduce pedestrian and cycle injury.

- Traffic speed reduction.

- Seat belt legislation.

- Legislation on child restraints in cars.

- Bicycle helmet legislation.

- Motor cycle helmet legislation.

- Child resistant closures to prevent poisoning.

- Provision of smoke alarms.

- Window guards to prevent falls.

- Domestic product design.

Interventions that have been demonstrated to change behaviour and thus reduce injury risk include:

- Educational campaigns to increase the use of safety devices (bicycle helmets, child restraints in cars, smoke alarms, seat belts).

- Pedestrian education aimed at the child and parent.

- Parent education on home hazard reduction.

Legislative, environmental modification and educational approaches all have a part to play, and their effect in combination is important.

Community based approaches allow injury prevention messages to be repeated in different forms and contexts. Important elements of such approaches are a long term strategy, effective focused leadership and commitment for injury prevention, good local data, interagency collaboration, and time to develop a range of local networks and programmes.

\section{IMPROVING THE RESEARCH BASE}

- Funding is inadequate for multifaceted research on the causes and prevention of injury. Funding levels need to reflect the importance of injury as a major cause of death and ill health in children and young people.

- There are a number of gaps in research that need to be filled. More interventions are needed that target the adolescent age group, sports and leisure injuries, and the problem of social deprivation.

- In order to test whether lessons from other countries are applicable to the UK, inter- 
vention studies conducted in other settings should be refined and tailored for different cultural environments.

- There is a need for more appropriate and better designed interventions to be evaluated in a more rigorous manner.

1 Towner EML. The role of health education in childhood injury prevention. Inj Prev 1995;1:53-8.

2 Avery JG, Jackson RH. Children and their accidents. London: Edward Arnold, 1993.

3 World Health Organisation. Accidents in children and young people. World Health Stat Q 1986;39:226-84.

4 Bass JL, Christoffel KK, Widome M, et al. Childhood injury prevention counseling in primary care settings: a crticial review of the literature. Pediatrics 1995;92:544-50.

5 Pless IB. The scientific basis of childhood injury prevention. A review of the medical literature. London: Child Accident Prevention Trust, 1993 .

6 Towner E, Dowswell T, Jarvis S. Reducing childhood accidents. The effectiveness of health promotion interventions: a literature The effectiveness of health promotion interventions: a liter
review. London: Health Education Authority, 1993.

7 Towner E, Dowswell T, Simpson G, et al. Health promotion in childhood and young adolescence for the prevention of unintenchildhood and young adolescence for the prevention of uninten-

tional injuries. London: Health Education Authority, 1996.
8 Klassen TP. The effectiveness of injury control interventions. Hamilton, Ontario, Canada: McMaster University, 1995.

Rivara FP, Grossman DC, Cummings P. Injury prevention: part 1. N Engl F Med 1997;337:543-8.

10 Rivara FP, Grossman DC, Cummings P. Injury prevention: part 2. N Engl f Med 1997;337:613-17.

11 Munro J, Coleman P, Nicholl J, et al. Can we prevent accidental injury to adolescents? A systematic review of the evidence. Inj Prev 1995;1:249-55.

12 Mackie AM, Ward HA, Walker RT. Urban safety project. 3. Overall evaluation of area wide schemes. Research report 263. Crowthorne, Berks: Transport and Road Research Laboratory, 1990.

13 Robertson LS. Injury epidemiology. New York: Oxford University Press, 1992.

14 Kimber RM. Appropriate speeds for different road conditions. In: PACTS, ed. Speed, accidents and injury: reducing tions. In: PACTS, ed. Speed, accider

15 Webster DC, Mackie AM. Review of traffic calming schemes in 20 mph zones. Transport Research Laboratory report 215 Crowthorne, Berks: TRL 1996.

16 Malenfant L, Van Houten R. Increasing the percentage of drivers yielding to pedestrians in three Canadian cities with a multifaceted safety program. Health Education Research 1989;5:275-9.

17 Rivara FP, Booth CL, Bergman AB, et al. Prevention of pedestrian injuries to children: effectiveness of a school training program. Pediatrics $1991 ; 88: 770-5$

18 Thomson JA, Tolmie A, Foot HC, et al. Child development and the aims of road safety education - a review and analysis. Crowthorne, Berks: Department of Transport. Road Safety Research. No 1. Norwich: The Stationery Office, 1996.

19 Firth DE. The road safety aspects of the Tufty Club. Crowthorne, Berks: Department of Transport. Transport Crowthorne, Berks: Department of

20 Antaki C, Morris PE, Flude BM. The effectiveness of the "Tufty Club" in road safety education. Br f Educ Psychol "Tufty Club" in

21 Bryan-Brown K. The effectiveness of the general accident Eastern Region Children's Traffic Club. Executive summary of project report 99. Crowthorne, Berks: Transport Research Laboratory, 1994

22 Schioldborg P. Children, traffic and traffic training: analysis of the children's traffic club. Fifth Congress of the International Federation of Pedestrians. Geilo, Norway, 1976.

23 van der Molen $\mathrm{HH}$, van den Herik J, van der Klaauw C. Pedestrian behaviour of children and accompanying parents during school journeys: an evaluation of a training programme. Br f Educ Psychol 1983;53:152-68.

programme. Br F Educ Psychol 1983;53:152-68.
24 Young DS, Lee DN. Training children in road crossing skills using a roadside simulation. Accid Anal Prev 1987;19:32741 .

25 Ampofo-Boateng K, Thomson JA. Children's perception of safety and danger on the road. Br F Psychol 1991;82:487505.

26 Ampofo-Boateng K, Thomson JA, Grieve R, et al. A developmental and training study of children's ability to find safe routes to cross the road. British Fournal of Developmental Psychology 1993;11:31-45

27 Thomson JA, Ampofo-Boateng K, Pitcairn T, et al. Behavioural group training of children to find safe routes to cross the road. Br f Educ Psychol 1992;62:173-83.

28 Harland G, Tucker S. "Let's decide walkwise"-the development and testing of a pedestrian training resource. Paper presented to the 14th Annual Conference of the British Health and Safety Society, 1994

29 Penna C. "Streets ahead" evaluation. GR 94-13. Kew, Victoria, Australia: Vic Roads, 1994.

30 Thomson JA, Whelan KM. A community approach to road safety education using practical training methods. The Drumsafety education using practical training methods. The Drum-
chapel project. Road safety research report No 3. London: chapel project. Road safety research

31 Thompson RS, Rivara FP, Thompson DC. A case-control study of the effectiveness of bicycle safety helmets. $N$ Engl $\mathcal{F}$ Med 1989;320:1361-7.
32 Dorsch MM, Woodward AJ, Somers RL. Do bicycle safety helmets reduce the severity of head injuries in real crashes? Accid Anal Prev 1987;19:183-90.

33 Hillman M. Cycle helmets: the case for and against. London: Policy Studies Institute, 1993.

34 Bergman AB, Rivara FP, Richards DD, et al. The Seattle children's bicycle helmet campaign. Am 7 Dis Child 1990;144:727-31.

35 Dannenberg AL, Gielen AC, Beilenson PL, et al. Bicycle helmet laws and educational campaigns: an evaluation of strategies to increase children's helmet use. Am f Public Health 1993;83:667-74.

36 Leicester P, Nassam F, Wise A. The introduction of compulsory bicycle helmet wearing in Victoria. GR 91-4. Vic Roads: Kew, Victoria, Australia, 1991

37 Cameron MH, Vulcan AP, Finch CF, et al. Mandatory bicycle helmet use following a decade of helmet promotion in Victoria, Australia - an evaluation. Accid Anal Prev 1994; 26:325-37.

38 Somers RL. On the cost of repealing motorcycle helmet laws. Am f Public Health 1983;73:1216.

39 Chenier TC, Evans L. Motorcyclist fatalities and the repeal of mandatory helmet wearing laws. Accid Anal Prev 1987;19:133-9.

40 Macarthur C, Parkin PC, Sidky M, et al. Evaluation of a bicycle skills training program for young children: a randomized controlled trial. Inj Prev 1998;4:116-21.

41 van Schagen INLG, Brookhuis KA. Training young cyclists to cope with dynamic traffic situations. Accid Anal Prev 1994;26:223-30.

42 McDavid JC, Lohrmann BA, Lohrmann G. Does motorcycle training reduce accidents? Evidence from a longitudinal quasi-experimental study. F Safety Res 1989;20:61-72.

43 Mortimer RG. A further evaluation of the motorcyle rider course. I Safety Res 1988;19:187-96.

44 Lowne R, Roberts A, Roy P, et al. The effect of the UK seat belt legislation on restraint usage by children. Technical paper series 840526. Warrendale, PA: Society of Automotive Engineers, 1984

45 Transport Research Laboratory. Restraint use by car occupants 1990-92. TRL leaflet LF2056. Crowthorne: TRL, 1992.

46 Sinnott WR. Safety aspects of domestic architecture. In: Jackson RH, ed. Children, the environment and accidents. London: Pittman Medical, 1977:76-90.

47 Jarvis SN, Towner EML, Walsh SSM. Accidents. In: Botting $\mathrm{B}$, ed. The health of our children: a review in the mid-1990s. London: Office of Population Censuses and Surveys, 1996: 95-112.

48 Walsh SSM, Jarvis SN, Towner EML, et al. Annual incidence of unintentional injury among 54000 children. Inj Prev 1996;2:16-20

49 Kemp A, Sibert J. Preventing scalds to children. BMF 1995; 311:643-4.

50 Runyan CW, Bangdiwala SI, Linzer MA, et al. Risk factors for fatal residential fires. N Engl f Med 1993;327:859-63.

51 National Committee for Injury Prevention and Control. Injury prevention: meeting the challenge. New York: Oxford University Press, 1989.

52 Gorman RL, Charney E, Holtzman NA, et al. A successful city-wide smoke detector giveaway program. Pediatrics 1985;75:14-18.

53 Shaw KN, McCormick MC, Kustra SL, et al. Correlates of reported smoke detector usage in an inner-city population: participants in a smoke detector give-away program. Am $\mathcal{f}$ Public Health 1988;78:650-3.

54 Hammond J, Varas R. Co-ordinated strategies in burn prevention programs: a case study. F Burn Care Rehabil 1990; 11:376-8.

55 Mallonee S, Istre GR, Rosenberg M, et al. Surveillance and prevention of residential-fire injuries. $N$ Engl $\mathcal{f} \mathrm{Med}$ 1996;335:27-31

56 McLoughlin E, Marchone M, Hanger SL, et al. Smoke detector legislation: its effect on owner-occupied homes. Am F Public Health 1985;75:858-62.

57 Miller RE, Reisinger KS, Blatter MM, et al. Pediatric counseling and subsequent use of smoke detectors. Am F Public Health 1982;72:392-3.

58 Goddard G. Summary fire statistics. United Kingdom 1995. Home Office statistical bulletin. London: Government Statistical Service, 1997

59 Goddard G, Poole J. Summary fire statistics. United Kingdom 1994. Home Office statistical bulletin. London: Government Statistical Service, 1996.

60 Hayes M, Levine S. Causes and prevention of home injuries. In: Aynsley-Green A, Jarvis S, Roberts I, et al, eds. Unintentional injury in childhood and adolescence. London: Bailliere Tindall, 1997:347-57. (Bailliere's Clinical Paediatrics, vol 5.)

61 Hayes M, Towner E. Reducing unintentional injuries to children under 15 years old in England. Setting objectives and plans for the period 1998-2010. Discussion document prepared for the Department of Health, 1998.

62 Home Office. Summary fire statistics: United Kingdom 1991 London: Home Office, 1992

63 Dowswell T, Towner E, Cryer C, et al. Accidental falls: fatalities and injuries. An examination of the data sources and review of the literature on prevention strategies. Report prepared for Department of Trade and Industry, 1998.

64 Department of Trade and Industry. Child safety equipment for use in the home. Home and leisure accident research. London: Department of Trade and Industry, 1991. 
65 Towner E, Jarvis S. Unintentional injury prevention. In: David T, ed. Recent advances in paediatrics. Vol 14. London: Churchill Livingstone, 1996.

66 Kavanagh CA, Banco L. The infant walker: a previously unrecognised health hazard. Am f Dis Child 1982;136:2056.

67 Webber G, Aizlewood C. Falls from domestic windows. BRE information paper No IP17/93. Watford: Building Research Establishment, 1993

68 Webber G, Aizlewood C. Falls from domestic balconies. BRE information paper No IP18/93. Watford: Building Research Establlishment, 1993.

69 Spiegel CN, Lindaman FC. Children can't fly: a program to prevent childhood morbidity and mortality from window falls. Am $\mathcal{F}$ Public Health 1977;67:1143-7.

70 Moller J. Strategic perspectives in burn and scald prevention. Paper presented at the Second World Conference on Injury Control (May 1993). Atlanta, USA, 1993.

71 Erdmann TC, Feldman KW, Rivara FP, et al. Tap water burn prevention: the effect of legislation. Pediatrics burn prevention:

72 Penny M. Burns prevention. Hazard 1992;12:1-11.

73 MacKay AM, Rothman KJ. The incidence and severity of burn injuries following Project Burn Prevention. Am F Public Health 1982;72:248-52.

74 Colver A, Pearson P. Safety in the home: how well are we doing? Health Visitor 1985;58:41-2.

75 Colver AF, Hutchinson PJ, Judson EC. Promoting children's home safety. BMF 1982;285:1177-80.

76 Dershewitz RA. Will mothers use free household safety devices? Am F Dis Child 1979;133:61-4.

77 Barone VJ, Greene BF, Lutzker JR. Home safety with families being treated for child abuse and neglect. Behav Modif 1986;10:93-114.

78 Paul CL, Sanson-Fisher RW, Redman S, et al. Preventing accidental injury to young children in the home using volaccidental injury to young children in the home using

79 Olds DL, Henderson CR, Kitzman H. Does prenatal and infancy nurse home visitation have enduring effects on infancy nurse home visitation have enduring effects on qualities of parental caregiving and child hea

80 Roberts I, Kramer MS, Suissa S. Does home visiting prevent childhood injury? A systematic review of randomised controlled trials. BMF 1996;312:29-33.

81 Barker M, Power C, Roberts I. Injuries and the risk of disability in teenagers and young adults. Arch Dis Child 1996;75:156-8

82 Mott A, Evans R, Rolfe K, et al. Patterns of injuries to children on public playgrounds. Arch Dis Child 1994;71:32830.

83 Chalmers DJ, Marshall SW, Langley JD, et al. Height and surfacing as risk factors for falls from playground equipment: a case-control study. Inj Prev 1996;2:98-104.

84 Mott A, Rolfe K, James R, et al. Safety of surfaces and equipment for children in playgrounds. Lancet 1997;349: equipment

85 Condie C, Rivara FP, Bergman AB. Strategies of a successful campaign to promote the use of equestrian helmets. ful campaign to promote the use

86 Morton JG, Burton JF. An evaluation of the effectiveness of mouthguards in high-school rugby players. $N Z$ Dent $\mathcal{F}$ 1979;75:151-3

87 Commonwealth Department of Human Services and Health. Better health outcomes for Australians. National goals, targets and strategies for better health outcomes into the next century. Canberra: Australian Government Publishing Service, 1994.

88 van Mechelen W, Hlobil H, Kemper HCG, et al. Prevention of running injuries by warm-up, cool-down, and stretching exercises. Am ₹ Sports Med 1993;21:711-19.

89 Ekstrand J, Gillquist J. Prevention of sports injuries in football players. Int $\mathcal{F}$ Sports Med 1984;suppl 5:140-4.

90 Spyker DA. Submersion injury. Epidemiology, prevention and management. Pediatr Clin North Am 1985;32:113-25.

91 Fergusson DM, Horwood LJ. Risks of drowning in fenced and unfenced domestic swimming pools. NZ Med f 1984; 97:777-9.

92 Gardiner SD, Smeeton WMI, Koelmeyer TD, et al. Accidental drownings in Auckland children. N Z Med f 1985;98:579-82

93 Barry W, Little TM, Sibert JR. Childhood drownings in private swimming pools: an avoidable cause of death. BMF $1982 ; 285: 542-3$.

94 Quan L, Gore EJ, Wentz K, et al. Ten-year study of pediatric drownings and near-drownings in King County, Washington: lessons in injury prevention. Pediatrics 1989 83:1035-40.

95 Milliner N, Pearn J, Guard R. Will fenced pools save lives? A 10-year study from Mulgrave Shire, Queensland. Med $f$ Aust 1980;ii:510-11.

96 Kemp A, Sibert JR. Drowning and near drowning in children in the United Kingdom: lessons for prevention. BMF 1992;304:1143-6.

97 Yamamoto LG, Yee AB, Matthews WJ, et al. A one-year series of pediatric ED water-related injuries: the Hawail EMS-C project. Pediatr Emerg Care 1992;8:129-33.
98 Patrick $M$, Bint $M$, Pearn J. Saltwater drowning and near-drowning accidents involving children. A five year total population study in south-east Queensland. Med $\mathcal{F}$ Aust 1979;i:61-4.

99 Finney JW, Christophersen ER, Frisman PC, et al. Society of Pediatric Psychology Task Force report: pediatric psychology and injury control. F Pediatr Psychol 1993;18: 499-526.

100 Runyan CW, Gerben EA. Epidemiology and prevention of adolescent injury. A review and research agenda. $\mathcal{F A M A}$ 1989;262:2273-9

101 Sibert JR, Nixon J. Causes and prevention of leisure, school and work injuries. In: Aynsley-Green A, Jarvis S, Roberts I, Towner E, eds. Unintentional injury in childhood and adolescence. London: Bailliere Tindall, 1997: 359-73. and adolescence. London: Bailliere Tinda

102 Low Pay Unit and Birmingham City Council Education Department. The hidden army: children at work in the 1990s. Birmingham: Low Pay Unit and Birmingham City Council, 1995

103 Cameron D, Bishop C, Sibert JR. Farm accidents in children. BMF 1992;305:23-5.

104 Cameron D, Bishop C. Farm accidents in adults. BMF 1992;305:25-6.

105 Corcoran H. Safety for youth in agriculture. Safety Standards 1967;16:1-3.

106 Schelp L. Community intervention and changes in accident pattern in a rural Swedish municipality. Health Promotion 1987;2:109-25.

107 World Health Organisation. Manifesto for safe communities. Proceedings of the 1st World Conference on Accident and Injury Prevention, Stockholm. Geneva: WHO, 1989

108 Schwarz DF, Grisso JA, Miles C, et al. An injury prevention program in an urban African-American community. Am f Public Health 1993;83:675-80.

109 Davidson LL, Durkin MS, Kuhn L, et al. The impact of the Safe Kids/Healthy Neighborhoods injury prevention program in Harlem, 1988 through 1991. Am f Public Health 1994;84:580-6.

110 Ozanne-Smith J, Sherrard J, Brumen IA, et al. Community based injury prevention evaluation report: Shire of Bulla Safe Living Program. Report No 66. Melbourne: Monash University Accident Research Centre, 1994.

111 Ytterstad B. The Harstad Injury Prevention Study: Hospital-based injury recording used for outcome evaluation of community-based prevention of bicyclist and pedestrian injury. Scand f Prim Health Care 1995;13:141-9.

112 Ytterstad B, Wasmuth HH. The Harstad Injury Prevention Study: evaluation of hospital-based injury recording and community-based intervention for traffic injury prevention. Accid Anal Prev 1995;27:111-23.

113 Ytterstad B, Sogaard AJ. The Harstad Injury Prevention Study: prevention of burns in small children by a community-based intervention. Burns 1995;21:259-66.

114 Guyer B, Gallagher SS, Chang BH, et al. Prevention of childhood injuries: evaluation of the Statewide Childhood
Injury Prevention Program (SCIPP). Am $\mathcal{F}$ Public Health 1989;79:1521-7.

115 Hillman M, Adams J, Whitelegg J. One false move... a study of children's independent mobility. London: Policy Studies Institute, 1990.

116 Gilbert K, McCarthy M. Deaths of cyclists in London 1985-92: the hazards of road traffic. BMF 1994;308:1534-

117 Allsop RE, Turner ED. Road casualties and public transport fares in London. Accid Anal Prev 1986;18:14756.

118 Department of Transport. The national cycling strategy. London: Department of Transport, 1996.

19 Whitelegg J. A geography of road traffic accidents. Transactions of the Institute of British Geographers 1987;12:161-76.

120 Preston B. Statistical analysis of child pedestrian accidents in Manchester and Salford. Accid Anal Prev 1972;4:32332.

121 King DM, Lawson SD, Proctor S, et al. Child pedestrian accidents in inner areas: patterns and treatment. PTRC Summer Annual Meeting seminar D. Bath: University of Bath, 1987 .

122 Benzeval M, Judge K, Whitehead M, eds. Tackling inequalities in health. An agenda for action. London: King's Fund, 1995.

123 Office of Population Censuses and Surveys. Occupational mortality: childhood supplement. Registrar General's decennial supplement for England and Wales, 1979-80, 198283. London: HMSO, 1988. (Series DS, vol 8.)

124 Roberts I, Power C. Does the decline in child injury mortality vary by social class? A comparison of class specific mortality in 1981 and 1991. BMF 1996;313:784-6.

125 Hills J. Inquiry into income and wealth. York: Joseph Rowntree Foundation, 1995:

126 Oppenheim C, Harker L. Poverty. The facts. 3rd Ed. London: Child Poverty Action Group, 1996.

127 Roberts I, Pless B. Social policy as a cause of childhood accidents: the children of lone mothers. BMF 1995;311: $925-8$. 